\title{
Reading the Country After Travelling Television
}

\section{Chris Healy}

This is, inevitably, happily and idiosyncratically, a personal response to an invitation to reflect upon Reading the Country thirty years down the track. Inevitably, because although my initial engagement with Reading the Country was scholarly, for me, it was then and is now, biographically important. It's a book I feel lucky to have engaged with when I did, in the 1980s, when it was one encounter among many with a diverse array of scholarly works, along with contemporaneous film and television, music, art, politics and theory, which re-ordered my relation to Australia. These reflections are also happily personal because my reading the book was followed not only by the joys of working, talking and walking with Stephen Muecke but also with me following in Stephen's footsteps and meeting and walking with the Goolarabooloo people of Broome, including Paddy Roe. But here, these personal aspects of reflecting on Reading the Country can remain in the back seat on this trip despite my idiosyncratic focus here on mapping some specific associations between Stephen's 30-year-old book and my current research on television.

That work is concerned with a genre of television I call 'travelling television', programming that has been a regular and popular presence on broadcast television in Australia since 1956. Travelling television is often series-based and consists of journeys to and through remote or distinctive places. The journey might be in search of fauna or history, characters or family, spectacle or wonder, or merely motivated by a desire to explore or discover. It is a genre of television that includes famous examples like Ask the Leyland Brothers (1976-1979, 1983-1984) and less well-known series such 
as Absalom's Outback (1981) and Deborah Mailman and Catherine Freeman's Going Bush (2006). Travelling television began in Australia with Charles Chauvel and Elsa Chauvel's 1956 BBC production Walkabout, a 13-part series in which the Chauvels journey by car, horse and train from their home in Sydney to Victoria and South Australia and on through Central Australia. ${ }^{1}$ Walkabout picks up and elaborates a range of cultural conventions from the rich variety of travel writing that was so important in bringing Australia into imaginative existence. It also introduces a number of formal conventions that characterise the genre, such as the use of charismatic presenters who guide, direct, orient and instruct the viewers by speaking both as authoritative narrators and directly to the viewer in more intimate ways as we follow in their footsteps.

Many of the contrasts between travelling television and Reading the Country are obvious. Published by a small, marginal and distinctively committed press (as Ray Coffey makes so clear in this volume), the book was a unique experiment in writing, painting and rendering speech about country. The generosity of spirit in and collaborative nature of Reading the Country, its adventurousness with form and its commitment to a deferred authority of storytelling, all this and more contributed to it being a remarkable intellectual contribution that has echoed, warped, repeated, faded and then returned again down the years in a series of effects and after effects. Travelling television, by contrast is, by and large, the product of conventional practices of television-making and Australian broadcast television. It's largely television telling predictable stories and aiming for ratings-based popularity; it's tightly stitched to tourist consumption, celebrates the fetishism of vehicles and other commodities. So, it's important to state from the outset that I am not proposing any symmetry, correspondence or analogy between Reading the Country and travelling television. However, as narratives, they do share a connection with what Michael Taussig has called 'the origin of storytelling ... in the encounter between the traveller and those who stay at home'. Here I want to argue that, as storytelling, Reading the Country and aspects of travelling share some concerns; with journeys, with clearing away habits of thought, with how things move, with the circulation of ideas and with 
modes of being-in-place. I want to suggest that in both we can find resources for the future in the present.

\section{Preparing the vehicle}

We have attempted to convey in pictures and words our feelings for this country ... as civilisation spreads and destroys more wilderness areas every year ... As you read our books and watch our films you will share with us some of the real Australia that will soon be only a memory. ${ }^{2}$

Any significant journey and perhaps any travel at all is preceded by a travelling imaginary and, in many cases, proceeds from some version of that imaginary. A journey might be raised purely in the imagination but it might also be dreamedup with the aid of a guidebook's itinerary or a postcard; it might be inspired by a traveller's tale, a map or even a television program. The imaginary of remote Australia produced in travelling television draws on images and stories already firmly in place: of white men exploring and colonising; of ardour for the bush, the hardships of occupying country and the opportunities promised by development; of the romance of the primitive, and the wonder of landscape and fauna. There is also, as in the quote above from the Leyland brothers, sometimes a melancholy fantasy of imminent disappearance in the imaginary of travelling television which is part of the work of preparing the vehicle and the mind to cope with the vicissitudes of the journey ahead. It's as if the act of planning to travel in Australia is shadowed by a fear of failure. There's a foreboding that the productive forces of modernity which enable such travel will also have clear-felled the forests, mined the desert and despoiled the reefs; that towns will have been abandoned, that bush characters and the Aboriginal people they depended on will have vanished; that the imagined journey is actually one that could only have been made in the past, that 'the real Australia will only be a memory'.

Ask the Leyland Brothers was a very popular program that ran for many years during the 1970 s and 1980 s. From the perspective of the early twenty-first century, the hosts, Mike and Mal Leyland, look a little like precursors to the slick 
specialists and gurus identified by Tania Lewis as the key characters in contemporary reality and lifestyle TV. ${ }^{3}$ But the Leylands were deploying a very different kind of expertise, a much more ordinary and gentle version of leading by example. And this is built into the structure of their programs, in that Mike and Mal's travelling is directed, in part, by the questions that viewers sent them by mail. An online search of 'Broken Hill Caravan Park review' today yields more that 200,000 results but when a viewer wrote and asked the Leylands about caravanning in Broken Hill, the brothers and their families travelled there to show us what it was like. In this and other episodes they conducted a dialogue with fellow citizens/consumers/travellers that was instructional because it invited emulation. The viewer sees ordinary family travel, and knows they can reproduce just that. In this way, the Leylands' knowledge was presented as model, practice and lesson. Ask the Leyland Brothers voiceover commentaries and pieces to camera were methodical and patient in their explanations, and delivered with a matter-of-fact affect. They never assumed prior knowledge of the topic at hand, be it the 'dreamtime stories' of Uluru, the lifecycle of the platypus, the industrial techniques involved in the production of Akubra hats or what it would be like to live the life of a drover. Again and again their 'answers' to viewers' questions feel like Mike and Mal - child-migrants from the United Kingdom who grew up in Newcastle, New South Wales - are keen not only to instruct but to learn and then share that knowledge, to quietly explain to the audience how they might produce their own ordinary expertise in the country they inhabit.

If Ask the Leyland Brothers and other examples of travelling television are one of the means by which people get out of cities, into the country and to places like Broome, then motor vehicles are central actors in their stories. In early film, like The Back of Beyond (1954) and newsreel coverage of the Redex Motor Car Trials of the early 1950s, the vehicles themselves were, in Georgina Clarsen's account, heroic 'steel capsules, technological prostheses for attacking expanses of territory'. ${ }^{4}$ By contrast, the vehicles initially used by the Leylands are very modest modes of transport. They travel by tinny down the Darling River, and on the road they load up a VW Kombi van. Once 
they get sponsorship, the series joins a long line of television programs that promote the use of four-wheel drive vehicles that, decades later, are the Toorak tractors roughing it at suburban shopping strips and on display outside private schools of metropolitan capital cities, and which are still valourised in hypermasculine advertising as cars that can conquer 'the toughest country'. There is an extreme version of this way of producing relationships between cars and place in Paddy Roe's country in a video posted by 'Top Gear Driver Training' in February 2016. The vehicle in the clip is a kind of mini-monster truck equipped with huge tyres and massive suspension to enable it to drive at high speed along sand tracks. The occupants, in all likelihood wearing helmets, would experience the place they're travelling through as a blur in their peripheral vision, as they'd be focused solely on keeping the vehicle from crashing. The track they're driving on is a little north of where Krim, Stephen and Paddy travelled but it was Paddy's great grandson, Daniel, who posted the video on Facebook. He wrote of the clip: 'Here's one for the Yawuru Rangers to follow up, these mob exploiting a section of land my family been trying to close off to the public for years. Maybe able to prosecute them for driving through an aboriginal heritage area.'

Perhaps as a reaction against these vehicular traditions, there's barely a mention of cars in Reading the Country and they're featured in only two photographs; the first of a wrecked K5 International that Paddy stripped and left on his windmill run and another of a stationwagon that's become home for a goat. As we know from other television programs such as Bush Mechanics, there's a rich tradition of Indigenous creativity centred on vehicles but in Reading the Country the focus is less on the vehicle as object and more on what they can do to get things moving. Our access to Paddy Roe's knowledge comes, in part, from Stephen being not only a scribe but also a 'driver' of a vehicle - the use of which enables not tourism or even travel but one way of beginning to produce the assemblages that come to be described as 'knowledge about country'. The book is replete with a gentle and unassuming clearing away of anthropological and historical conceptual inheritances (Stephen refers to an argument he has with Krim about abandoning 'intellectual baggage') and it certainly deploys 
many theoretical resources. In terms of travel, there's not a lot of 'before' in Reading the Country; no training for the rigours of the journey, no anticipation of what's to come, no discussion of how to keep the bulldust out of the luggage, no thought about how many spare tyres to load or how many jerry cans to carry additional fuel, and no melancholic anticipation of failure or the absence of attachment which accompanies that fear. In this sense Reading the Country is less about travel and much more about being in space; it's more cinematic, beginning in media res, or maybe in the middle of the second reel. But this too is in the spirit of the nomadology that Muecke invokes: 'While ... nomadology might talk about things people do in their travels, it can also be about abstract journeys taking place while one is sitting down.' ${ }^{5}$ And what's disclosed of their journeying actually occurs when the men sit down, here and then there to listen and talk. And this talking becomes, again and again, Paddy Roe 'telling stories in joyous affirmation of his peoples' will to survive'. ${ }^{6}$

'We must make things move': screen and maps

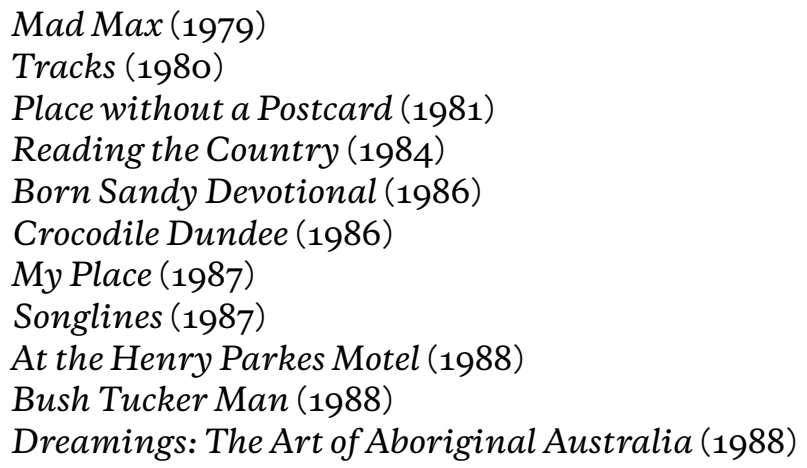

Mike and Mal Leyland made film for a relatively new medium and they understood deeply two foundational aspects of television: that it is democratic and that, in market societies, television is a site where experience is commodified and integrated into other aspects of everyday life. Paradoxically, travel television was often organised precisely around an escape from the world in which one might watch television, 
into (another) world that one might have watched on television. The travelling of travelling television is not the travelling of 'discoverers' or of the first colonisers but the much more ordinary travelling which is undertaken as a way of occupying country, of settling, of belonging, of feeling part of place on television. In the second half of the twentieth century, travel television was central to the production of an image-saturated popular pedagogy that connected television viewers to national and local places and offered one of the key ways in which settler colonialism was both perpetuated and forgotten. It was organised around both participatory and mimetic travel and much of it aimed to inspire and train people to undertake their own journeys, producing new kinds of relations between routes, screens, car ownership, indigeneity, maps, petrol stations, tourism, self-formation and national identification. Early in Reading the Country, Stephen writes:

Paddy Roe and his people have their intellectual baggage too, their culture and their philosophies. Significantly, these are located in the country, the stories and songs are strung out across the Plains and are brought out as one moves along the tracks. Paddy Roe has an expression for the production of this culture: 'We must make these things move.' 7

At the tail end of the wet season, Stephen is concerned with getting started on the book, writing: 'How could I make this thing thing move.' In 1984, Land Rights legislation in Australia was not yet a decade old, while Mabo and the Native Title Act were nearly a decade in the future. In this sense things were both on the move in the shifting recognition of Indigenous rights to land and, as Paddy Roe insisted, in need of being moved. The list of texts above, (mostly) from the 1980s, share a concern with various kinds of movement in film television, popular music and various forms of writing at a time the transformation of the Australian economy under the Hawke and Keating Labor governments (1983-1996) was building speed. As Krim, Paddy and Stephen head from Broome to the Roebuck Plains Station and further east from the Old Sheep Camp towards Nyikina country, they need to 'unlock' the barriers to their travelling, 
farm gates festooned with signs reading: 'Trespassers Prosecuted. No Entry.' Keys to the gates can be obtained by Paddy diplomatically approaching owners or managers. But, says Muecke, the real key to the country is Paddy Roe's astounding range of knowledge across so many domains and the long silences 'which speak of the lack of common ground between Aboriginal discourses and White discourses'. ${ }^{8}$

There's a shift in the concerns of travelling television that comes from a more explicit engagement with Indigenous knowledge in Bush Tucker Man and with the arrival of Indigenous television presenters such as Hetti Perkins in Art and Soul. In fact, the origin of Bush Tucker Man is very precisely in a gap, the lack of common ground identified by Stephen. Les Hiddins talked about the idea for Bush Tucker Man originating as he was flying over country in Northern Australia as an Australian Army officer and wondering:

Crikey, how would we get on if we had to ditch here? How would we survive" And I found that we really had nothing on a sheet of paper about survival in the Australian continent. So, I thought, why not get out there and start tabulating this information. ${ }^{9}$

In his work with the Australian Defence Force, Hiddins went on to create ordinance survey maps for soldiers training in northern Australia that, on the reverse, feature descriptions of edible plants and animals. Most of this information comes from traditional owners and it's this knowledge, much of it shared cooperatively and treated with respect, that forms the backbone of Bush Tucker Man. And there's a different kind of movement again in a very beautiful scene in Art and Soul when Hetti Perkins, the series presenter/host, travels to New York with Doreen Reid Nakamarra. It's a brief montage that cuts from Nakamarra working and talking with Perkins at Papunya Tula in Alice Springs, to iconic shots of the New York skyline and the Statue of Liberty from the Staten Island Ferry, and shots of the group of Aboriginal women walking hand in hand through Washington Square. Perkins, Nakamarra and others had travelled to New York as part of the Papunya Tula Artists' team to present the exhibition 'Nganana tjungurringanyi 
tjukurrpa nintintjakitja'. As Perkins says; 'sharing our dreaming at 80 Washington Square East Galleries, New York, at the end of the Icons of desert exhibition tour, shortly before [Nakamarra] passed away in 2009'.10 So, even in a genre as conventional as travelling television, things move, and perhaps new possibilities are opened up.

\section{Place}

Once I travelled the country to the North of Broome with Paddy Roe recording sites and stories on what became the Lurrijarri trail, which you have also written about. I had an idea then for a work called 'The Children's Country' which was supposed to follow through Paddy Roe's heritage of this trail and its sites via his daughter Teresa. The original story about this is in Reading the Country and is called 'We better go back to country'. So, I worked with Paddy and his family, but extended the scope by interviewing Broome primary school kids about their impressions of these sites where they often go for weekend fishing trips: Barred Creek, Minariny, etc. But that work was never completed. ${ }^{11}$

In the first few pages of Reading the Country, in the section of the book titled 'Reading this Book', Stephen writes that place is 'central to the theory and method of the book'. ${ }^{12}$ He goes on to provide three reasons for this centrality: place introduces specificity and difference; place displaces dominant meanings and reified categories; and place foregrounds and can (re-) sensitise us to our modes of apprehending our environments. The most obvious way travelling television works with a related notion of place comes in how the genre connects being-at-home in travelling with the being-at-home of a television spectator.

Take, for example, one of the only two clips from Walkabout available online. ${ }^{13}$ The scene opens with a smiling and relaxed Harry Closter, the unit's cameraman, sitting in the back of the parked Land Rover passing Elsa a pumpkin and some tinned food. The fixed camera pans to follow Elsa carrying the makings of a meal to her food preparation area in the kitchen set up under the shade of a tarpaulin while in the 
middle distance we see Charles crouched by the fast-flowing Katherine River filling a billy and then walking toward the camera as he brings the water into the kitchen. It's a beautiful and economical shot that produces a strong sense of immediate and easy domesticity. ${ }^{14}$ The dialogue over this and the following shot is characteristic of the kind of first-person, location-based narration Elsa uses so often in Walkabout:

'These are really blue heaven days as we camp on the river below the little township called Katherine.

The lonely men who first came into this country called their homesteads and little townships after far-away wives or sweethearts, like Alice Springs, Charlotte Waters and Katherine.

Well, here's Katherine.'15

The effect of the images and this little narrative works very specifically to produce a sense in which both the expedition and the viewers of Walkabout are visitors to Katherine; both are on the edge of the town, passing through this place rather than being of it. The contrast with Reading the Country could not be stronger. Rather than writing, painting or talking as tourists on expedition, the creators of the book seem to be constantly asking about their relation to place, what they bring to it, what is already there and what they might give to it and take from it in their temporary occupation.

There might have been something of this dynamic at work in the travelling of the first person I met who'd been to Broome. Lester Allan was a slaughterman at the Angliss Meatworks in Melbourne in the 1930s, working on the mutton chain. A longtime (un-paid) union official and a member of the Communist Party of Australia, he later worked as a meat inspector. When I interviewed him in 1984, he said that he frowned on the killing of animals and described himself as a 'conservationist, recycler and scrounger'. After he retired, Allen and his wife would load up the caravan every Autumn and, before the weather turned cold, begin a drive to Broome and beyond, not returning until Spring. Lester said they both loved the bush life. The travelling 
of this working-class couple was a product of the kind of demotic possibilities celebrated by much travelling television. As well as seeking the sun like the grey nomads of the twentyfirst century, the Allens were curious about what lay beyond years of factory work and a home a stones-throw from an oil refinery at Altona. Lester might not have met Paddy Roe, and I doubt that he read Reading the Country, but he seems connected in some way to the vitality of Paddy Roe's people, to the establishment of the Lurujarri Trail, the victory over Woodside Petroleum and the WA State Government, and the survivance of Goolarabooloo. Somewhere between the fantasy of 'a wide open road' celebrated by travelling television and Reading the Country, there might be spaces made to ask the question 'What kinds of cultural conditions and resources need to be invented to make the country viable for people to have place to live?' In this sense, Reading the Country still seems like both an urgent project with lessons for this time and one whose time is yet to come.

\section{Notes}

See Stuart Cunningham, 'Charles Chauvel: The Last Decade', Continuum, vol. 1, no. $1,1987$. Mike and Mal Leyland, Discovering Australia, Golden Press, Sydney, 1976, p. 7. Tania Lewis, Smart Living: Lifestyle Media and Popular Expertise, Peter Lang, New York, 2007.

Georgine Clarsen, 'Automobiles and Australian Modernism: The Redex AroundAustralia trials of the 1950s', Australian Historical Studies, vol. 41, no. 3, 2010, p. 361.

Krim Benterrak, Stephen Muecke and Paddy Roe, Reading the Country: Introduction to Nomadology, Fremantle Arts Centre Press, Fremantle, 1984, p. 15.

6 Ibid., p. 231.

7 Ibid., p. 22.

8 Benterrak, Muecke and Roe, p. 67.

9 'Les Hiddins: Bush Tucker Man', Talking Heads, ABC TV, 2007.

10 Hetti Perkins and Warwick Thornton, Episode 1, Art + Soul (DVD), Hibiscus Films, Sydney, 2011.

11 Chris Healy, 'Travelling Theory: An Interview with Stephen Muecke', Meanjin, vol. 58, no. 3, 1999, pp. 174-91.

12 Benterrak, Muecke and Roe, p. 13.

13 'Australian Screen', https://aso.gov.au/titles/tv/australian-walkabout/.

14 It's interesting that after this shot we cut briefly to another set-up of Elsa working in the same kitchen that's been arranged differently so that she's lit by artificial light and the river features more prominently in the background. This was presumably shot as an alternative to the longer shot described above but it doesn't produce the immediate sense of shared domestic intimacy. 